these children who are mentally as normal as you or I and any other paraplegic. They can be developed into excellent people, can go to universities and can be developed in a normal way. Then we have the other extreme, the mentally defective children for whom special arrangements in special schools have to be made. When we talk about education it is not just education of the child, it is education of the parents in the first place, in particular the mother. We must prevent mothers to become overprotective of these people, that they don't care, for instance, about their incontinence. I was amazed to find intelligent adult spina bifida cases who couldn't care less whether they were urinary incontinent or not and, of course, were socially unacceptable. The mistake which had been made was that these children have not been made conscious that to be incontinent of faeces or urine makes them socially unacceptable. That can be done, as we proved even in young adults who came to us at the age of I6. It takes sometimes a long time to develop that sense of shame of being smelly - an interesting psychological point which I have met with these spina bifidas. I agree with Gregg that with a certain group we should try as we do with the able-bodied to get as many as possible home and into society, but there will always be a group, as we also know about traumatic paraplegics and tetraplegics, who cannot return into society, and for these we have to make special arrangements. Here I think this Society can do a lot of good work. Dr. Gregg is in a relatively fortunate situation: Eire is a country of $2 \frac{1}{2}$ million people. He is an excellent organiser and has really taken the opportunity to centralise these spina bifida cases now in his unit. You can do that in a small population, but it is more difficult, of course, in a greater community. But it is an excellent beginning and I do congratulate Dr. Gregg.

Chairman. Thank you, Sir Ludwig. Now, I know that a number of people would have liked to discuss this subject, but time is getting on and we have a number of papers still to hear. Perhaps, indeed, this might be one of the main subjects of discussion at some future date.

\title{
OUR EXPERIENCES ABOUT PREGNANCY AND DELIVERY OF THE PARAPLEGIC WOMAN
}

\author{
By Herta Göller, Cand.Med., and Volkmar Paeslack, M.D. \\ Spinal Injuries Centre, Orthopaedic University Clinic, \\ Heidelberg, Germany
}

WITH the increasing number of paraplegic women, the study of pregnancy and delivery of these patients gains considerable significance, theoretically as well as practically.

In the past three years we followed six gestation periods in our Spinal Unit in Heidelberg. The patients' ages ranged between 24 and 32 years. All patients had complete lesions of the thoracic cord as a result of trauma of the spine. In the following the case histories of three patients are given which seem to be worth while discussing.

Case I. Sch. G., 28.2.39, 27 years. Complete spastic paraplegia below Th8 due to compression fracture-dislocation of the 9 th thoracic vertebra, as the result of a road accident. At the time of accident pregnancy had lasted 5 to 6 months, being the second gravidity. A healthy boy was born two years ago without complications. In the second month of pregnancy, i.e. three months previous to her accident, the patient had a longlasting, moderately strong vaginal haemorrhage, the cause of which could not be determined. 
The patient was admitted to our Spinal Unit I I days after the accident. X-rays had already been taken of the thoracic and lumbar spine, skull and feet-showing in addition to the spinal lesion fractures of the lower jaw and both fore-feet. Furthermore, she had twice been given a 500 c.c. blood transfusion and a prophylactic treatment of tetanus had been started.

During clinical progress no complications occurred of skin, blood circulation, respiration, urinary tract or joints, nor severe trouble due to pregnancy. Gynaecological examinations showed no abnormalities of movements and heart sounds of the foetus. Growth of uterus and abdomen were according to time. Four months after the accident the membranes ruptured spontaneously and in time. Uterus contractions started and remained almost unnoticed and absolutely painless. In the course of 25 minutes a healthy female baby was born. We did not observe any disturbances of blood circulation, headaches or alteration of consciousness while the baby was delivered. Within 30 minutes the placenta was discharged, the mother felt fine. No data of B.P. nor pulse rate were obtained because of the breech-birth-like progress of events-all before the gynaecologist arrived. Later pressure tests gave no evidence of autonomous hyperreflexia. The newborn (3050 g., $52 \mathrm{~cm}$.) had normal reflex activity, slight icterus neonatorum. There was only an oedema of the right upper eyelid, which was interpreted as a complication of birth.

The following day, however, the baby's respiratory disorder was suggestive of cerebral damage. The child was transferred to the children's hospital, and further investigations revealed a microcephalus with a congenital bony defect of the frontal skull base, subdural haemorrhage on the right side and increasing cerebral spasticity. Having regard to the type of defect, the cause of this seemed to be a damage sustained in the first trimenon rather than an additional abdominal trauma, which the mother might have suffered from the road accident.

Lactation started in full after birth, but we had to stop it because the baby left our unit. Post partum there was amenorrhoea for several months.

The child, now 3 years old, with moderate cerebral spasticity, can stand up with apparatus and can speak some words.

Case 2. F. O., I0.2.43, 23 years, primapara. Complete spastic paraplegia below Th5 due to a road accident. The patient, driving her car herself, ran into an approaching car, possibly in a moment of transitory sickness - she fainted repeatedly previous to this event. At the time of accident she was pregnant for four months without any complications. Before the patient was transferred to our Spinal Unit, X-rays had been taken of the thoracic spine and prophylactic tetanus treatment had been started. During the first 48 hours after the injury there was considerable hyperglycaemia up to $245 \mathrm{mg}$./Ioo g. glucose.

During the clinical course the patient had repeated infections of the urinary tract but no other complications due to paraplegia. There was long-lasting emesis gravidarum. B.P. ranged constantly between $90 / 60$ and $75 / 50 \mathrm{~mm}$. $\mathrm{Hg}$, pulse rate about $100 / \mathrm{min}$.

The fractured vertebrae-Th5-7-consolidated in due course and the patient could sit up after eight weeks. Intensive physiotherapy was started, considering the special situation of pregnancy.

Gynaecological findings were normal throughout pregnancy, only for a short time increased growth of the abdomen raised the suspicion of a developing hydramnion.

In due course the woman was transferred to the gynaecological hospital. When uterus contractions started gradually, these were painless but could definitely be noticed by palpation as well as by the patient herself. The membranes were ruptured artificially. After half an hour of labour the baby was delivered by vacuum extraction. During the second stage of labour we observed significant flushing of the face and shoulders, but no sweating. There was continuous but not very severe headache and ascending sensations of heat and pressure during uterine contractions; B.P. rose to $120 / 90 \mathrm{~mm}$. $\mathrm{Hg}$; no paroxysmal hypertension was observed. 
The newborn boy (3970 g.) showed marked opisthotonus. The circumference of the baby's head was increased and highly suspicious of hydrocephalus. Further investigations revealed a blockage in the aquaeductus Sylvii, a large internal hydrocephalus and pachymeningosis haemorrhagica interna was considered.

During the following months the baby developed all the symptoms of severe brain damage, progressive hydrocephalus - in spite of the implantation of a Spitz-Holter-valve -and died when 15 months old. According to the paediatrician's and neurologist's opinion, this damage might well have been due to a cerebral trauma in utero when the accident happened.

Post-partal the bladder training - though having worked absolutely satisfactorily up to the date of giving birth - failed completely. Until today the patient has never regained a spinal bladder automatism. Urological investigations revealed distinct flaccidity of the detrusor vesicae, the sphincter tonus being increased. She now has intermittent catheterisation twice a day.

Eight months after the boy was born this woman became pregnant again. Consultation in the out-patients' department was followed by clinical observation and control during the last six weeks of gravidity. This time there was only little sickness, no severe dysregulation of blood circulation occurred. Normal development in growth; first movements of the child were felt in time; the foetus' heart-sounds could be registered well. Twenty days previous to the actual date of birth -35 days previous to the calculated date - the mother noticed the lowering of the fundus. She had a terrible headache, but B.P. showed only a slight rise: $100 / 60 \mathrm{~mm}$. $\mathrm{Hg}$; all the time previous to this event systolic pressure did not pass $90 \mathrm{~mm}$. Hg. When labour started, the patient had no pains during the first stage but violent diffused headache. The membranes were ruptured artificially, a considerable amount of amniotic fluid passed. B.P. never rose any further than 120/90 $\mathrm{mm} . \mathrm{Hg}$, without varying synchronically with the uterus contractions. Again we noticed flushing of the patient's face and shoulders only, no sweating, while labour progressed. Pulse rate was constantly $100 / \mathrm{min}$. throughout labour and delivery and ascending sensations of heat and pressure from the abdomen towards the head occurred with each uterus contraction. After the first stage, lasting for $4 \mathrm{hr}$. I 5 min., a healthy baby girl (3400 g., $52 \mathrm{~cm}$.) was born spontaneously within a second period of $5 \mathrm{~min}$. This time the rather strong and effective uterus contractions in the second stage were considerably painfulpain felt in abdomen. Lactation started to its full extent; but again we had to stop breast feeding, the cause being now an infectious mastitis. No further change in the neurological status of the mother after giving birth. The baby developed well.

Case 3. M. E., 3I.I.40, 24 years. Complete, fairly spastic paraplegia below Th5 following compression fracture-dislocation of the 5th-7th thoracic vertebrae. Three months previous to this accident the patient had given birth to a healthy female baby. Time of pregnancy had been uneventful.

The patient was admitted to our Spinal Unit the day of her accident. In the following months we could not find any change in comparison with the initial neurological findings, except increasing spasticity. Two days after the accident we observed bleeding per vaginam, followed by amenorrhoea during the period of hospital treatment and a long period of irregular bleeding after discharge.

Ten months after the road accident her I-year-old daughter died. The patient suffered from severe depression and was in danger of committing suicide. Nine months later, though, she became pregnant again and we were glad to notice that the patient's mental condition improved rapidly. However, the mother was in a rather reduced state of physical health, suffering from considerable disorder of blood circulation, such as tendency to collapse, marked oedema of the lower legs and infection of the urinary tract, which could not be treated satisfactorily.

The progress of gravidity corresponded to normal findings. Labour started in due time. Uterus contractions were painless, but the patient suffered from increasingly severe 
headaches at the back of the head and outbrusts of perspiration distinctly above the neurological level of paraplegia. With each contraction B.P. rose to $185 / 100 \mathrm{~mm}$. $\mathrm{Hg}$, pulse rate $68 / \mathrm{min}$; data in between uterus contractions were B.P. $120 / 85 \mathrm{~mm}$. Hg, pulse rate $80-84 / \mathrm{min}$.

The first stage of labour lasted $2 \mathrm{hr}$. I $5 \mathrm{~min}$., then the membranes were ruptured artificially. Five minutes later a healthy female infant was born spontaneously (3000 g., $5 \mathrm{I} \mathrm{cm}$.). Only ten minutes later the placenta was expelled. B.P. never rose any further than $185 / 100 \mathrm{~mm}$. Hg but pulse rate decreased to $64 / \mathrm{min}$. during delivery of the child and during the expulsion of placenta. Within $2 \mathrm{hr}$. post partum B.P. ranged about $\mathrm{I} 70 / \mathrm{IO0} \mathrm{mm}$. $\mathrm{Hg}$, pulse between 72 and $68 / \mathrm{min}$., and within the next $\mathrm{I} \frac{1}{2} \mathrm{hr}$. came back to their normal levels. The headache vanished after $\frac{1}{2} \mathrm{hr}$. post partum.

\section{DISCUSSION}

We have chosen three out of six cases of pregnancy which we observed at our Spinal Unit. The first patient became paraplegic when six months pregnant. Most probably the foetus had come to harm before that event. She gave birth to a child with cerebral and bony defect. The second patient was four months pregnant when she became a paraplegic. She also gave birth to a child with severe brain damage, in this case probably due to injury of the uterus and/or the foetus, caused by the trauma in the road accident. In the second and third patients, where pregnancy occurred some time after spinal cord injury, there were deliveries of healthy children.

Our clinical observations confirm that the paraplegic woman, being well rehabilitated, is not restricted in her fertility at all. Spinal injury mostly causes amenorrhoea for a short time (Paeslack, I965), but after some months the mensual hormonal cycle becomes regular (Comarr, I966). Conception is not impaired (Bors, I963) and the course of pregnancy is the same as in other women. There is no evidence of complications-specifically caused by paraplegia apart from infection of the urinary tract-as far as the foetus' development is concerned. Nevertheless, one should be particularly careful in medical control. As we have seen only a comparatively small number of these patients, we cannot decide whether nephropathia in gravidity is more likely to occur in paraplegic women than in non-paraplegic ones, but we have to realise a strong liability to chronic infections of the urinary tract (Guttmann, I963; Hardy, I965; Paeslack, I965; Comarr, I966). We never observed impairment of the power of uterine contractions in thoracic lesions and although we cannot report of regular painless labour in high or midthoracic lesions, pain seems definitely less than one is used to find in other women. We found paroxysmal rising of B.P. and bradycardia during labour, in particular during delivery and expulsion of the placenta. We also found flushing with and without sweating, both definitely restricted to the non-paralysed part of the body, headache of various type and ascending sensations synchronous to uterine contractions-such as have been reported by other authors (Mertens, Harms S., Harms H., Jungmann, I960; Jung, Schmidt, I962; Guttmann, I963, I965; Hardy, I965) - but no danger for the mother or the baby arose.

We have been very much worried by the tragedy of the birth of the two babies with severe brain damage. There is the question of etiology as well as possibly of therapeutic measures. In the second case reported, we must consider damage due to the accident, either by direct trauma of the uterus or by anoxaemia or hypoxaemia in spinal shock. It seems important to analyse a large number of such 
events during pregnancy to be able to come to a conclusion whether or not an interruption of pregnancy might at least be taken into consideration, when spinal trauma occurs in the first half of the gestation period. We are uncertain about this question, the more so as two other patients, who became paralysed within the first trimenon, gave birth to healthy babies.

Studying the literature, we found only two cases where living newborns died within the first week of life of cerebral haemorrhage (Katz, I927) and of thrombosis of the sinus sagittalis and inferior (Spitzer, I933). Katamnestic investigations of Guttmann (1963) reveal absolutely normal development of the living newborns.

Moreover, one should also study the influence of X-ray, blood transfusion and tetanus prophylaxis on the development of the embryo.

From a psychological and social point of view our observations do not raise any objection to pregnancy after clinical rehabilitation of a paraplegic woman. On the contrary, we think that the birth of a healthy baby to a young woman so severely injured has a very positive effect on rehabilitation in its widest meaning. We do not think that general hesitation is justified only because of the burden of pregnancy and nursing a child. To give just one example: when the third patient reported in this paper became pregnant with her second child, she was advised by her family doctor to have an interruption immediately done. She was then still in deep depression about the death of her first child and in a bad state of health. One of us (P.) discussed the question with the patient and luckily the young woman did not give way to the suggestion of interruption. There has been a considerable mental and physical improvement in this case as a result of the birth of her healthy baby.

\section{SUMMARY}

Three case histories of pregnancy and delivery in paraplegic women are presented. The first patient became paraplegic when six months pregnant. Most probably the foetus had come to harm before her paraplegia. She gave birth to a child with cerebral and bony maldevelopment. The second patient was four months pregnant when she became paraplegic. She also gave birth to a child with severe brain damage, in this case probably due to injury of the uterus and/or the foetus, caused by the trauma at the time of the road accident. In both cases where pregnancy occurred some time after spinal cord injury-which is in the second and third patient-there was delivery of healthy children.

In discussing the clinical observations we state $(a)$ conception is not impaired, (b) the development of the foetus does not seem to be interfered with by complications specifically due to paraplegia, $(c)$ no reduced power of uterine contractions were found in complete thoracic lesions. There still remains the question whether or not paraplegic women are more likely to give birth to damaged or deformed babies than non-paraplegic women if a spinal cord injury occurs during pregnancy or if pregnancy follows spinal cord lesion.

\section{ZUSAMMENFASSUNG}

Drei Fälle von Schwangerschaft und Entbindung bei querschnittgelähmten Frauen werden beschrieben. Die erste Patientin war 6 Monate schwanger als sie gelähmt wurde. Höchstwahrscheinlich wurde hierbei der Foetus geschädigt. Das Kind zeigte nach der Geburt cerebrale und ossale Entwicklungsstörungen. Die zweite Patientin war 4 Monate schwanger als sie eine Paraplegie erlitt. Das Kind zeigte bei der Geburt ebenfalls schwere 
cerebrale Störungen und in diesem Fall wird eine gleichzeitige Schädigung entweder des Uterus oder des Foetus durch den Unfall mit Wahrscheinlichkeit angenommen. Zwei Patienten mit traumatischer Paraplegie gebährten normale Kinder.

Die klinischen Beobachtungen werden diskutiert.

Es besteht immer noch die Frage, ob bei Paraplegikerinnen eine grössere Wahrscheinlichkeit besteht, geschädigte oder deformierte Kinder zu gebähren als bei nicht gelähmten Frauen, wenn eine Rückenmarksverletzung während der Schwangerschaft erfolgte oder wenn Schwangerschaft nach einer solchen Verletzung eingetreten war.

\title{
RÉSUMÉ
}

Trois observations de grossesse et d'accouchement chez des femmes paraplégiques sont présentées.

Il résulte de la discussion,

(I) que la conception n'est pas perturbée,

(2) que le développement du foetus ne semble pas aggravé par les complications dues à la paraplégie, et, enfin que la force des contractions utérines ne paraît pas être diminuée dans les lésions thoraciques complètes.

La question demeure, à savoir, si une femme paraplégique accouche plus fréquemment qu'une femme non paraplégique d'un enfant traumatisé ou déformé, l'atteinte médullaire survenant au cours de la grossesse, ou avant celle-ci.

\section{REFERENCES}

BoRs, ERNEST (1963). Sexual function in patients with spinal cord injury, Spinal Injuries, Edinburgh, page 78.

Comarr, A. E. (I966). Medical Services f., Canada, 22, 65I.

GutTMANN, L. \& WhitTeridge, D. (1947). Brain, 70, 36I.

Guttmann, L. (1963). Proc. of the Roy. Soc. of Med., vol. 56, Nr. 5, 383-387.

Guttmann, L. (I964). Paraplegia, 2, I82.

Guttmann, L., Frankel, H. L. \& PAeslack, V. (1965). Paraplegia, 3, I44.

HaRdy, A. G. \& Warell, D. W. (1965). Paraplegia, 3, I82-I88.

JUNG, H. \& SCHMIDT, K. (I962). Ztr. Bl. Gyn. 84, I 105.

KATZ, H. (I927). Ztr. Bl. Gyn. 5I, 2992.

Mertens, H. G., Harms, S. und H. \& Jungmann, H. (I960). Dtsch. Med. Woschr. 85 Jb., i 80. PAESLACK, V. (1965). Internistische Störungen beim Paraplegiker Sonderdruck aus In memoriam Kurt Lindemann, Edit. Prof. Dr. G. Jentschura.

SPITZER, W. (1933). Arch. Gyn. I52, 5 I 7.

\section{A STUDY ON SEXUAL FUNCTION IN 56 MALE PATIENTS WITH COMPLETE IRREVERSIBLE LESIONS OF THE SPINAL CORD AND CAUDA EQUINA}

\author{
By Professor K.-A. Jochheim and Dr. H. WAhle \\ Rehabilitationszentrum der Universität zu Klön (W. Germany)
}

Four years ago $\mathrm{H}$. Wahle (I965a, b) published a study on paraplegic patients with complete lesions, in which special mention was made of the length of the period of rehabilitation. The choice of the average length of the period necessary to rehabilitate a patient was based on the results obtained by Sir Ludwig Guttmann (I956) depending on the level of the lesion (Table I). We are referring to the accident as stage $\mathrm{I}$, this is followed by the observation period, section $\mathrm{A}$, after which the average Stoke Mandeville patient could have been discharged from hospital at stage II. 